\title{
Suporte Organizacional no Setor Público: a Percepção de Gestores de uma Secretaria Estadual
}

\author{
Organizational Support in the Public Sector: the Perception of Managers of a State Sec- \\ retary
}

\author{
Carolinne Rodrigues de Souza Silva \\ Universidade Federal de Pernambuco - UFPE - Brasil \\ carolinnesilva@gmail.com \\ ORCID: 0000-0001-9259-4528 \\ José Ricardo Costa de Mendonça \\ Universidade Federal de Pernambuco - UFPE - Brasil \\ jrcm@ufpe.br \\ ORCID: 0000-0001-7718-984X
}

Submetido em 14/10/2018; Aprovado em 17/03/2019

\begin{abstract}
Resumo
Objetivo: embora o Suporte Organizacional seja reconhecido como um antecedente relevante de aspectos como comprometimento e motivação dos trabalhadores, ainda são poucos os estudos que investigam o construto no setor público, sobretudo considerando abordagens qualitativas. Buscando minimizar essas lacunas, este artigo se propôs a analisar como os gestores públicos percebem o suporte organizacional oferecido pela Secretaria de Planejamento e Gestão de Pernambuco (Seplag-PE). Metodologia: foi realizado, assim, um estudo de caso que utilizou as seguintes técnicas de coleta de dados: entrevistas semiestruturadas, observação participante e análise documental. Principais resultados: os resultados, obtidos a partir da análise de conteúdo indicam que existe uma percepção negativa dos gestores da Seplag-PE quanto ao suporte oferecido pela instituição. Além disso, a pesquisa sugeriu a mudança da categoria Sobrecarga de Trabalho, utilizada por Tamayo e Tróccoli (2001), e identificou os fatores políticos como uma nova categoria de suporte organizacional, a qual contribui para uma percepção negativa do suporte oferecido pela instituição. Contribuições: de modo geral, o estudo contribuiu para aprofundar o entendimento do processo de formação das impressões dos servidores públicos quanto ao suporte organizacional.
\end{abstract}

Palavras-chave: Suporte Organizacional. Setor Público. Comportamento Organizacional. Pernambuco.

\section{Abstract}

Goal: although Organizational Support is recognized as a relevant antecedent of aspects such as commitment and motivation of the workers, there are still few studies that investigate the construct in the public sector, especially considering qualitative approaches. In order to minimize these shortcomings, this article aims to analyze how public managers perceive the organizational support offered by the Secretariat of Planning and Management of Pernambuco (Seplag-PE). Methodology: a case study was carried out using the following data collection techniques: semi-structured interviews, participant observation and documentary analysis. Main results: the results, obtained from the content analysis, indicate that there is a negative perception of the managers of Seplag-PE regarding the support offered by the institution. In addition, the research suggested the change of the Work Overload category used by Tamayo and Tróccoli (2001) and identified the political factors as a new category of organizational support, which contributes to a negative perception of the support offered by the institution. Contributions: in general, the study contributed to deepening the understanding of the process of forming public servants' impressions regarding organizational support.

Keywords: Organizational Support. Public Sector. Organizational Behavior. Pernambuco.

\section{Introdução}

Nos últimos anos, as organizações têm sofrido diversas mudanças que impactam não só em aspectos de suas estruturas produtivas, mas também em fatores comportamentais dos indivíduos no 
ambiente organizacional. As demandas decorrentes de transformações sociais, econômicas e tecnológicas passaram a exigir cada vez mais efetividade e qualidade dos bens e serviços públicos.

Dentre outros elementos, a qualidade do serviço público está intimamente relacionada à habilidade dos órgãos da Administração Pública em manter servidores qualificados, comprometidos e motivados no ambiente de trabalho (Lewis; Frank, 2002).

Ao estudar temas como comprometimento organizacional, motivação e bem-estar no trabalho, a literatura costuma investigar quais os aspectos que antecedem esses construtos. Estudos recentes apontam o suporte organizacional como um elemento antecedente de diversos conceitos comportamentais na organização, como: i) motivação (Karatepe, 2015); ii) mudança organizacional (Al-Hussami; Hammad; Alsoleihat, 2018); iii) bem-estar no trabalho (Estivalete; Andrade; Faller; Stefanan \& Souza, 2016); e iv) comprometimento organizacional (Fernandes, Siqueira \& Vieira, 2014).

O suporte organizacional pode ser identificado, de acordo com Fandiño, Formiga, Meneses e Souza (2016), como um mediador da relação organização-trabalho-individuo, uma vez que avalia a percepção dos indivíduos acerca dos esforços adotados pela organização em torno do bem-estar do funcionário. 0 suporte organizacional, portanto, refere-se às percepções do indivíduo acerca da qualidade e justiça do tratamento recebido da organização em retribuição ao esforço que é empenhado no trabalho. Essas percepções consideram a frequência, a intensidade e a sinceridade das manifestações organizacionais de aprovação, reconhecimento, retribuição material e social ao esforço dos seus recursos humanos (Eisenberger, Huntington, Hutchison \& Sowa, 1986; Zagenczyk, Scott, Gibney, Murrell \& Thatcher, 2010).

Berthelsen, Hjalmers e Soderfeldt (2008) afirmam que a percepção de suporte no ambiente de trabalho constitui um relevante aspecto psicológico presente nas relações de trabalho, afetando diretamente a relação entre o indivíduo e a organização. Tamayo e Tróccoli (2002) afirmam que a interação dos empregados com seus colegas de trabalho também pode constituir um componente do suporte organizacional, possibilitando que a percepção de suporte organizacional (PSO) seja um processo social, além de psicológico.

Nesse sentido, a percepção positiva acerca do suporte organizacional ofertado tende a fortalecer o envolvimento do empregado com a organização (Oliveira-Castro, Pilati, Borges-Andrade, 1999), sendo considerando elemento antecedente de comportamentos positivos dos indivíduos junto à organização (Souza; Marques, 2014).

Diante do contexto apresentado, resta clara a importância de se investigar a percepção de suporte organizacional, sobretudo considerando, conforme Pereira (2016) uma realidade ainda pouco explorada (setor público) e uma abordagem qualitativa - ainda pouco utilizada no estudo desse conceito - a fim de melhor aprofundar a exploração do conceito como sugerem Moraes e Bastos (2017) e Estivalete et. al. (2016). Diante disso, este estudo se propõe a avaliar a percepção dos servidores da Seplag-PE quanto ao suporte organizacional oferecido pela organização.

\section{Percepção de suporte organizacional}

Bastos et al. (2014) afirmam que diversas pesquisas têm se dedicado a analisar o que gera o comprometimento organizacional (antecedentes) e quais os impactos gerados por este construto (consequentes). Os autores pontuam que sem essa compreensão é impossível o gerenciar o comprometimento. Assumindo tal premissa, o presente estudo explora a percepção de suporte organizacional como antecedente do comprometimento organizacional.

O conceito de suporte organizacional está intimamente relacionado com os mecanismos de troca social e de reciprocidade que sustentam as relações entre funcionários e organizações. Possui como base, portanto, as teorias da troca social e da norma da reciprocidade (Aselage; Eisenberger, 2003).

De acordo com Gomide Jr., Guimarães e Damásio (2004), a teoria da troca social fornece explicações sobre a motivação existente por trás das atitudes e comportamentos apresentados pelos indivíduos. Assim, as trocas sociais ocorrem pautadas pela confiança e pela boa fé entre as partes, o que envolve a oferta de favores que criam obrigações futuras. Nesse sentido, a utilização desses pressupostos nos ambientes de trabalho possibilita a compreensão acerca da influência das organizações no comportamento dos indivíduos (Wayne, Shore, Bommer \& Tetrick, 2002). 0 princípio da reciprocidade (Gouldner, 1960), por sua vez, estabelece que as relações sociais são regidas por um princípio moral que discorre sobre a obrigação de retribuir favores recebidos.

Partindo dessas premissas, Eisenberger et al. (1986, p. 501) definiram o construto da PSO como "as crenças globais desenvolvidas pelo empregado sobre a extensão em que a organização valoriza as 
suas contribuições e cuida do seu bem-estar". Nesse sentido, é possível afirmar que a PSO consiste nas crenças que os indivíduos possuem sobre o quanto a organização na qual trabalham reconhece e retribui seus esforços individuais e se preocupa com seu bem-estar (Eisenberger et al., 1986).

0 bem-estar dos funcionários é um conceito amplo, que envolve diversos serviços, benefícios e facilidades dados aos indivíduos, visando impulsionar suas condições de trabalho e seu desenvolvimento profissional (Giorgi; Dubin; Fiz, 2016). Diógenes, Paschoal, Neiva \& Menezes (2016, p. 157) afirmam que:

0 fenômeno do suporte organizacional situa-se num contexto de interação dos interesses organizacionais com os interesses do trabalhador. Organização e funcionário envolvem-se numa parceria, na qual cada uma das partes apresenta exigências e demandas próprias. A organização estabelece demandas quanto ao desempenho, aos resultados e às normas de comportamentos. Em troca, os funcionários esperam receber as condições e retribuições necessárias para a realização de tarefas.

Por essas características, as organizações têm apresentado uma preocupação crescente em oferecer ambientes mais agradáveis e melhores condições de trabalho aos indivíduos. Essas intervenções podem ser incluídas no conceito de suporte organizacional, uma vez que sua definição está relacionada às ações da organização, no sentido de desenvolver e reconhecer seus trabalhadores, garantindo recursos e visibilidade (Aselage; Eisenberger, 2003).

Como apontam Oliveira-Castro et al. (1999), o suporte organizacional tem se apresentado como um antecedente relevante de construtos, como o desempenho e o comprometimento. Zanelli, BorgesAndrade e Bastos (2014) apontam que a literatura destaca a influência da percepção de suporte organizacional em consequentes organizacionais como: menor registro de absenteísmo, menor intenção de saída, melhor desempenho, maior satisfação e envolvimento com o trabalho, além de maior comprometimento organizacional e melhor aprendizagem.

Tamayo e Tróccoli (2002) afirmam que o suporte organizacional também absorve aspectos sociais. Sobre isso, Gomide Jr., Guimarães e Damásio (2004) afirmam que o suporte social no trabalho se refere à percepção do empregado de que encontra na organização os suportes emocional, instrumental e informacional necessários para a realização das atividades.

As categorias da Escala de Suporte Organizacional Percebido (ESOP) (Quadro 1), desenvolvida por Tamayo e Tróccoli (2000), incluem o suporte social e foram escolhidas a priori para compor a análise deste estudo.

Quadro 1 - As categorias da escala de suporte organizacional percebido

\begin{tabular}{|c|l|}
\hline Categorias & \multicolumn{1}{|c|}{ Definição } \\
\hline Estilos de Gestão da Chefia & $\begin{array}{l}\text { Percepção dos indivíduos quanto às formas utilizadas pelo supervisor para traduzir as } \\
\text { políticas e práticas organizacionais em sua unidade. }\end{array}$ \\
\hline Gestão do Desempenho & $\begin{array}{l}\text { Percepção dos indivíduos sobre as políticas e práticas organizacionais que regulam o pro- } \\
\text { cesso de trabalho na instituição como um todo. }\end{array}$ \\
\hline Sobrecarga de Trabalho & $\begin{array}{l}\text { Percepção dos indivíduos quanto às demandas de produção excessivas definidas para o } \\
\text { grupo de empregados. }\end{array}$ \\
\hline Suporte Material & $\begin{array}{l}\text { Percepção dos indivíduos sobre a disponibilidade, adequação, suficiência e qualidade dos } \\
\text { recursos materiais e financeiros fornecidos pela organização para ajudar a execução efi- } \\
\text { caz das tarefas. }\end{array}$ \\
\hline Suporte Social no Trabalho & $\begin{array}{l}\text { Percepção dos indivíduos acerca da existência e disponibilidade do apoio social e da qua- } \\
\text { lidade do relacionamento interpessoal com a chefia e com os colegas. }\end{array}$ \\
\hline Ascensão e Salários & $\begin{array}{l}\text { Percepção dos indivíduos sobre as práticas específicas de retribuição financeira, promo- } \\
\text { ção e ascensão funcionais. }\end{array}$ \\
\hline
\end{tabular}

Fonte: Tamayo e Tróccoli (2002)

Embora a PSO tenha se mostrado um importante tema a ser investigado, a produção brasileira sobre o construto está longe de abarcar a maioria das situações vivenciadas pelos indivíduos e organizações (Medeiros, 2013), o que corrobora a necessidade observada por Eisenberg et al. (1986) de mais estudos que analisem de forma aprofundada a percepção de suporte organizacional em diferentes contextos.

\section{Métodos}

Esta pesquisa possui natureza qualitativa, uma vez que se propôs a estudar um fenômeno específico por meio de elementos situacionais, dentro de seu contexto real (Miles, Huberman, 1994). A 
pesquisa qualitativa aplicada tem como objetivo compreender em profundidade determinados fenômenos e experiências, enfatizando, para isso, o significado que as pessoas envolvidas atribuem a eles (Merriam; Tisdell, 2016).

Neste estudo, optou-se pelo desenvolvimento de um estudo de caso único, de corte transversal, com a finalidade de propiciar um entendimento aprofundado a respeito de como os gestores governamentais percebem o suporte organizacional oferecido pela Secretaria de Planejamento e Gestão de Pernambuco. A escolha da Secretaria de Planejamento e Gestão de Pernambuco (SEPLAG-PE) como local de investigação foi motivada por ser este o órgão responsável por gerir o modelo de gestão adotado pelo poder Executivo do Estado de Pernambuco. Modelo este que apresenta forte preocupação quanto à oferta de bens e serviços públicos de qualidade, sendo reconhecido nacional e internacionalmente como um novo paradigma de gestão pública (Cruz; Marini; Lemos, 2014). Além disso, a SEPLAG-PE concentra em seu quadro servidores cujos cargos foram criados através da Lei Complementar 118, de 26 de junho de 2008, com o objetivo de fortalecer o modelo de gestão implementado, o que também é um aspecto relevante para justificar o estudo de aspectos comportamentais nesse cenário.

O período de realização das entrevistas se deu nos meses de novembro e dezembro de 2018 e as entrevistas semiestruturadas foram guiadas por um roteiro elaborado previamente com base nas categorias apontadas a priori. A escolha não probabilística (intencional) se mostra alinhada à proposta de um estudo qualitativo, uma vez que, conforme Patton (2002), este tipo de estudo busca o aprofundamento em corpus de pesquisa relativamente pequenos ou casos únicos selecionados propositalmente.

Tomando por base os propósitos deste estudo, os entrevistados foram selecionados tendo como parâmetros: (i) ser servidor público efetivo do estado de Pernambuco; (ii) estar vinculado à Secretaria de Planejamento e Gestão de Pernambuco; e (iii) ser gestor governamental de Planejamento, Orçamento e Gestão.

O objetivo principal do estudo qualitativo não é contabilizar opiniões ou pessoas, mas, sim, explorar o conteúdo das opiniões, ou seja, as diferentes representações sobre o assunto analisado. Dessa forma, a alternativa adotada neste estudo para limitar a quantidade de participantes é a saturação, que Merriam (2009) conceitua como o estágio do processo de coleta no qual começa a haver redundância de informações.

A coleta de dados ocorreu por meio da realização de entrevistas semiestruturadas, implicando na existência um roteiro, no qual foram listados tópicos previamente estabelecidos de acordo com a problemática central (Haguette, 1997). 0 roteiro de entrevista foi elaborado com base na Escala de Suporte Organizacional Percebido (ESOP), construída e validada por Tamayo et al. (2000).

Neste trabalho, utilizou-se uma das técnicas de análise de conteúdo (AC), qual seja: a análise categorial temática com grade mista, o que sugere a identificação das categorias a priori, havendo a possibilidade de incluir, excluir ou modificar categorias a posteriori, durante a exploração dos dados coletados (Bardin, 2016).

\section{A organização e os sujeitos pesquisados}

A Secretaria de Planejamento e Gestão de Pernambuco (Seplag-PE) foi criada em 2007, na gestão do então governador Eduardo Campos, em substituição à Secretaria de Administração e Reforma do Estado. A secretaria, órgão da administração direta do Poder Executivo Estadual, integra desde então o Núcleo Estratégico da Administração do estado. Na ocasião, a criação da Seplag-PE fez parte de um conjunto de mudanças administrativas realizadas na implantação do modelo de gestão Todos por Pernambuco, sendo ela o órgão responsável por coordená-lo, integrando os três pilares que sustentam sua proposta: planejamento, orçamento e gestão (Cruz; Marini; Lemos; 2014).

A Seplag-PE tem sua estrutura institucional composta por cinco Secretarias Executivas, além da Superintendência e do Núcleo de Comunicação, todos subordinados ao gabinete do secretário da pasta, como pode ser observado na Figura 1. No período da pesquisa (setembro 2018), 193 gestores governamentais de planejamento, orçamento e gestão estavam vinculados à Seplag-PE. De todos os GGPOG, 58 foram desconsiderados para fins da pesquisa por estarem em licença de qualquer natureza, em efetivo exercício ou cedidos a outros órgãos. 


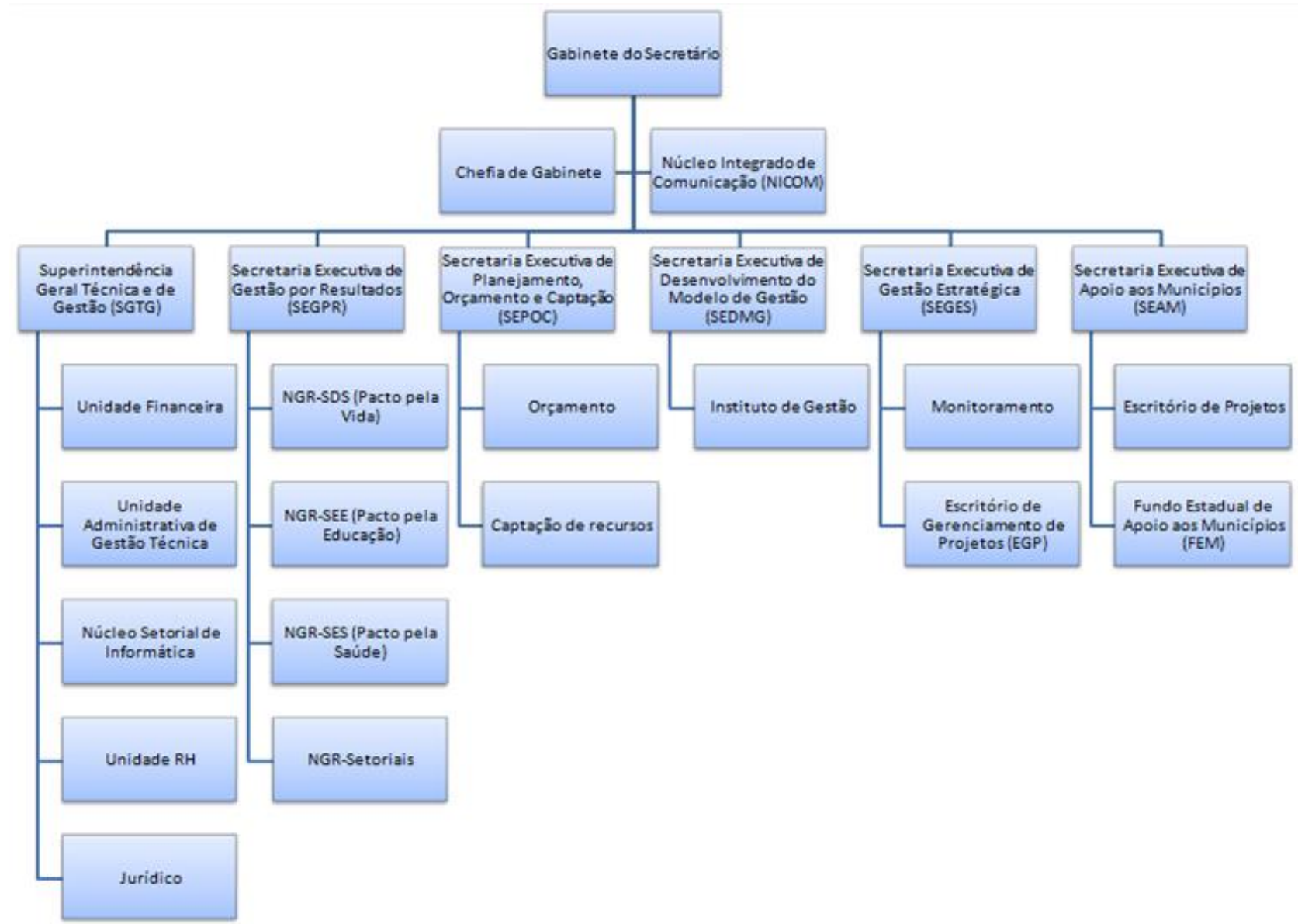

Figura 1- Estrutura institucional da Secretaria de Planejamento e Gestão de Pernambuco (Seplag-PE)

O Quadro 2 apresenta sinteticamente a distribuição dos 135 GGPOG que poderiam compor o corpus desta pesquisa, além de discriminar o escopo de atuação de cada setor onde há lotação de GGPOG. Quadro 2 - Distribuição de GGPOG por setor da Seplag-PE

\begin{tabular}{|c|l|c|c|}
\hline Setor & \multicolumn{1}{|c|}{ Escopo de Atuação } & $\begin{array}{c}\text { Quantidade de GGPOG } \\
\text { integrantes do Setor }\end{array}$ & $\begin{array}{c}\text { Quantidade de GGPOG } \\
\text { entrevistados por setor }\end{array}$ \\
\hline SGTG & $\begin{array}{l}\text { Administração geral e execução orçamentária e financeira da } \\
\text { SEPLAG. }\end{array}$ & 2 & 0 \\
\hline SEGPR & $\begin{array}{l}\text { Monitoramento dos Pactos (Vida, Educação e Saúde) e pro- } \\
\text { gramas de resultados. }\end{array}$ & 49 & 5 \\
\hline SEPOC & $\begin{array}{l}\text { Formulação das metas prioritárias e alinhamento orçamen- } \\
\text { tário. }\end{array}$ & 22 & 3 \\
\hline SEDMG & $\begin{array}{l}\text { Melhoria e inovação contínuas do modelo de gestão e capaci- } \\
\text { tação de pessoal. }\end{array}$ & 16 & 6 \\
\hline SEGES & $\begin{array}{l}\text { Acompanhamento das metas prioritárias e projetos de } \\
\text { grande porte. }\end{array}$ & 32 & 2 \\
\hline SEAM & $\begin{array}{l}\text { Suporte técnico aos municípios na elaboração de projetos e } \\
\text { oportunidades de financiamento. }\end{array}$ & 12 & 1 \\
\hline NICOM & $\begin{array}{l}\text { Assessoria de imprensa e canais de comunicação com a soci- } \\
\text { edade. }\end{array}$ & 2 & 2 \\
\hline
\end{tabular}

Fonte: Elaborado com base em Secretaria de Planejamento e Gestão de Pernambuco (Seplag-PE) (2018)

Foram entrevistados ao todo 27 gestores governamentais de planejamento, orçamento e gestão (GGPOG), sendo 15 do sexo feminino e 12 do sexo masculino. 0 quantitativo contemplou todos os setores da Seplag-PE, onde há efetiva lotação de GGPOG, com exceção da Superintendência Geral Técnica e de Gestão, na qual não houve resposta positiva dos gestores que a integram quando convidados a participar da pesquisa. $37 \%$ do total de participantes estavam vinculados à Secretaria Executiva de Gestão por Resultados, 22,2\% à Secretaria Executiva de Gestão Estratégica e 18,5\% à Secretaria Executiva de Planejamento, Orçamento e Captação. Os demais tinham sua lotação distribuída entre a Secretaria Executiva de Apoio aos Municípios, a Secretaria Executiva de Desenvolvimento do Modelo de Gestão e o 
Núcleo Integrado de Comunicação.

\section{Resultados}

\section{Percepção de Suporte Organizacional dos Gestores Governamentais}

Como destaca Eisenberger et al. (1986, p. 501), a PSO pode ser definida como o conjunto de "crenças globais desenvolvidas pelo empregado sobre a extensão em que a organização valoriza as suas contribuições e cuida do seu bem-estar". De maneira geral, observa-se uma percepção negativa quanto ao suporte organizacional oferecido pela Seplag-PE aos gestores governamentais de planejamento, orçamento e gestão, o que se justifica, em linhas gerais, pela ausência ou desconhecimento de práticas institucionais voltadas à valorização e ao cuidado com o bem-estar dos servidores (depoimentos exemplificadores no Quadro 3). Tais práticas foram diretamente relacionadas ao papel do setor de Recursos Humanos (RH) e sua atuação junto aos servidores.

Quadro 3- Relação entre a PSO e as práticas de RH

\begin{tabular}{|c|l|}
\hline Entrevistado & \multicolumn{1}{c|}{ Segmento } \\
\hline Ent4 & $\begin{array}{l}\text { Eu acho que a Seplag ela não tem uma política voltada pra isso. (...) Mas essa parte de bem-estar, a quali- } \\
\text { dade de vida, eu acho que isso realmente não ocupa o pensamento... eu digo da Seplag, mas focando } \\
\text { no trabalho que o setor de RH faz. (...) Eu acho que, em primeiro lugar, ela teria que, de um lado, } \\
\text { ampliar o escopo de trabalho do RH, que ele tem hoje, pra ele ter um papel onde ele tá mais atento } \\
\text { ao bem-estar dos funcionários. }\end{array}$ \\
\hline Ent9 & $\begin{array}{l}\text { Eu acho que a gente deveria ter um RH mais proativo, um RH que fosse mais voltado pro servidor. E } \\
\text { quando eu digo “voltado" mesmo é identificar os problemas dos servidores e de fato tentar ajuda a } \\
\text { solucionar ou adequar o servidor da melhor forma possível. A gente precisa avançar muito em nosso } \\
\text { RH ainda. }\end{array}$ \\
\hline Ent27 & $\begin{array}{l}\text { Caramba, com o bem-estar? Eu, pra mim, eu acredito que a Seplag não tem um RH. Pra mim, aqui é } \\
\text { um departamento de pessoal, eles pagam folha e organizam férias, ponto... Eu não consigo ver o RH } \\
\text { daqui trabalhando com gestão de pessoas, mesmo, comportamental, melhorando a motivação das } \\
\text { pessoas, integração (...)Entende? }\end{array}$ \\
\hline
\end{tabular}

Fonte: Elaborado pelos autores (2018)

Verifica-se que não só o setor de RH quanto suas práticas possuem um papel simbólico e prático importante na percepção do suporte organizacional de modo geral. Os depoimentos apontam ainda convergência com os achados de Moura e Souza (2016) e Carmo et al. (2018) que, observando autarquias federais, perceberam a prevalência de um setor de RH meramente operacional.

Há na organização estudada uma ausência de estratégia direcionada ao bem-estar do servidor e de sua valorização, o que foi bastante relacionado à falta de iniciativas do setor de Recursos Humanos que ultrapassem os procedimentos administrativos padrão como controle de ponto, licenças, férias e recadastramento do servidor. Essa constatação ampara a percepção negativa dos entrevistados quanto ao conceito geral de suporte organizacional.

A seguir, serão discutidas as categorias (figura 2) separadamente, como forma de aprofundar a análise.

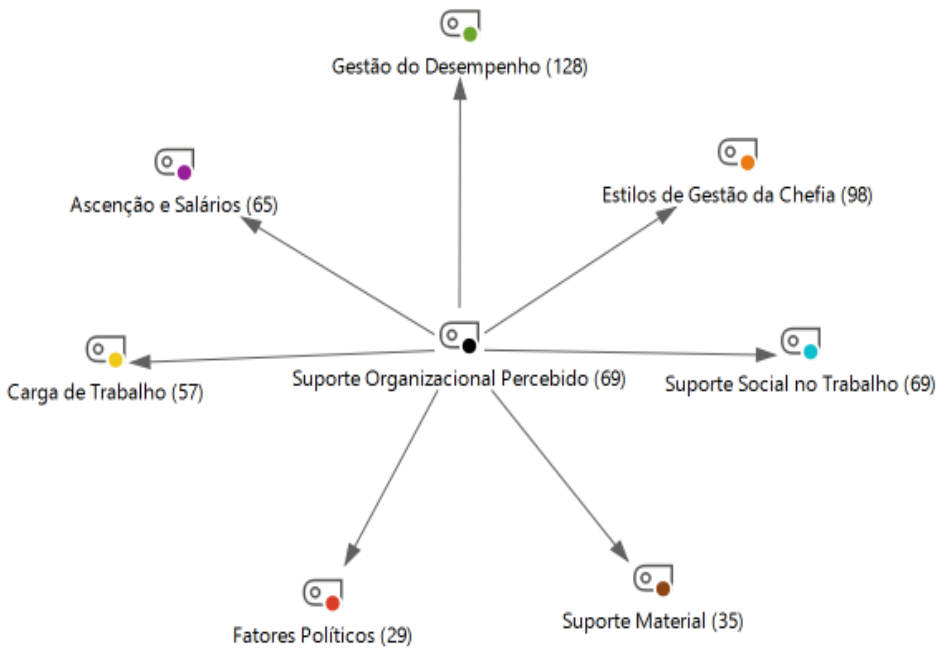

Figura 2 - Categorias Identificadas do Suporte Organizacional Percebido 
- Gestão do desempenho:

A categoria Gestão do Desempenho diz respeito à percepção construída pelos indivíduos acerca das políticas e práticas organizacionais que regulam o processo de trabalho na instituição como um todo (Tamayo; Trócolli, 2002). Por este motivo, é a categoria que abarca a maior quantidade de elementos, tais como o reconhecimento dos indivíduos e a valorização de novas ideias, o conhecimento sobre as metas de desempenho esperadas, o desenvolvimento de capacidades do servidor, o esforço de atualizar os indivíduos quanto ao uso de novas tecnologias e a coerência das ações e diretrizes organizacionais (Oliveira-Castro; Pilati; Borges-Andrade, 1999).

De modo geral, os itens que integram a análise da categoria contribuem negativamente para a percepção de suporte organizacional dos gestores governamentais da Seplag-PE, sobretudo quando são consideradas as subcategorias apresentadas no Quadro 4.

Quadro 4- Subcategorias da Gestão do Desempenho

\begin{tabular}{|c|c|}
\hline $\begin{array}{l}\text { Subcategorias da Ges- } \\
\text { tão do Desempenho }\end{array}$ & Depoimentos \\
\hline $\begin{array}{l}\text { Reconhecimento dos in- } \\
\text { divíduos e valorização } \\
\text { de novas ideias }\end{array}$ & $\begin{array}{l}\text { Eu já estou na Seplag há quase } 8 \text { anos. Então, o que acontece? Eu ainda permaneço falando e dizendo } \\
\text { coisas que eu acho que sejam interessantes de acontecer e tal. Muitas vezes, na maioria das vezes } \\
\text { essas coisas não são implementadas. Então, o que acontece? As pessoas também acabam se } \\
\text { frustrando e não falando mais. [Entrevista 1] }\end{array}$ \\
\hline $\begin{array}{l}\text { Conhecimento sobre as } \\
\text { metas de desempenho } \\
\text { esperadas }\end{array}$ & $\begin{array}{l}\text { Acho que o principal pra você mensurar isso é o resultado, o que é que ele tá entregando com relação } \\
\text { ao que foi esperado dele. Então cabe também à gestão comunicar aquilo que tá sendo esperado, } \\
\text { então se você não tem isso já cria um ponto muito subjetivo, "eu estou sendo cobrado pelo } \\
\text { que, na verdade? Eu tô fazendo, o que eu fizer é lucro. Ninguém chega pra explicar direito o } \\
\text { que é pra fazer". [Entrevista 6] }\end{array}$ \\
\hline $\begin{array}{l}\text { Coerência das ações e } \\
\text { diretrizes organizacio- } \\
\text { nais }\end{array}$ & $\begin{array}{l}\text { Há um conhecimento por alto, mas pra saber onde você se situa e como você pode colaborar } \\
\text { pra aquela diretriz, não há uma ideia clara. Fica meio perdido. Então, muitas vezes acaba muita } \\
\text { gente batendo cabeça porque a informação fica presa em algum lugar. (...) Aí é a pergunta que a gente } \\
\text { não sabe direito. Acho que todo mundo acha que tá seguindo os valores da SEPLAG, mas no fim } \\
\text { das contas esses valores não são bem claros.[Entrevista 11] }\end{array}$ \\
\hline
\end{tabular}

Fonte: Elaborado pelos autores (2018)

Observa-se que não há uma clareza quanto ao desempenho esperado do servidor e quanto às diretrizes que norteiam a instituição, além de pouco espaço para a valorização de novas ideias. 0 sentimento de frustração relatado pelos entrevistados em parte pode ser relacionado às expectativas que foram criadas quanto à Secretaria de Planejamento e Gestão e à própria carreira desenvolvida especificamente para revestir de maior robustez o Modelo de Gestão de Pernambuco. Por ser este pautado e amplamente divulgado como uma proposta de modernização da gestão pública - não só no que diz respeito às ferramentas de gestão, mas também às práticas gerenciais de processos, pessoas, resultados e impacto - há, na prática, uma quebra de expectativas ao se perceber aspectos fortemente vinculados a uma imagem engessada das organizações públicas.

Fica claro também (entrevista 11) que cada servidor acaba por estabelecer de modo individual quais são as diretrizes organizacionais a seguir, mostrando que é necessário avançar na construção de uma perspectiva comum de atuação do órgão. 0 entrevistado 6 alerta sobre a integração e unidade que deve ser buscada ao relatar: "você pode ser excelente, mas ali ficar meio que isolado. Tá faltando essa excelência conjunta, de trabalhar junto, de ter um fluxo comum, de ter uma cadeia de valor comum."

Em relação ao desenvolvimento profissional dos servidores, todos os entrevistados citaram o Programa de Formação Continuada (PFC) como iniciativa.

Em relação a isso, eu acho que até eles investem... Eu vejo mais em relação aos treinamentos. A gente tem o PFC, que faz parte da nossa carga horária, que a gente tem que ter a carga horária mínima. Vejo isso como algo positivo, porque de certa forma estimula cada servidor a sempre estar se atualizando, fazendo cursos que sejam da sua área, e melhore seu crescimento profissional. Em relação a isso eu vejo realmente eles tentam investir [Entrevista 7].

Bem, a preocupação com o desenvolvimento profissional, institucionalmente, ela existe. A gente tem um PFC pra isso. Eu acho que agora a gente deveria pular já pro desenvolvimento do conhecimento. A gente deveria já ter uma preocupação com categorizar e produzir conhecimento pra ser replicado institucionalmente, academicamente e pra outras esferas do governo [Entrevista 12].

Embora haja a identificação de pontos de melhoria no PFC (como exemplificado no depoimento 
acima do entrevistado 12), existe o reconhecimento da prática como elemento positivo na percepção dos GGPOG. Percebe-se a necessidade de desenvolver conteúdos customizados para as diferentes áreas de atuação da Seplag-PE, sobretudo relativos ao conhecimento de outras áreas e órgãos do estado, de modo que o conhecimento das ferramentas gerenciais acumulado pelos gestores possa se conectar com outros tipos de temas, permitindo propostas de intervenção mais robustas.

- Estilos de gestão da chefia:

O item Estilos de Gestão da Chefia foi indicado como uma das categorias mais importantes no processo de construção da percepção dos indivíduos acerca do suporte organizacional. Como apontam Tamayo e Trócolli (2002), a organização atua também por meio do comportamento individual de membros-chave, normalmente aqueles que ocupam cargos de gerência ou funções de liderança. É o que também deixa claro o depoimento do entrevistado 3 ao comentar sobre a preocupação da Seplag com o bemestar dos GGPOG:

Acho que depende muito do gestor, é algo que depende muito dele, da forma como ele lida, eu acho. Eu percebo muito isso. Não é algo da SEPLAG, é mais de quem tá à frente dela Eu acho [Entrevista 3].

Observou-se também que não existe direcionamento institucional por parte da Seplag-PE quanto à atuação das chefias, no sentido de traduzir políticas e práticas organizacionais. Há uma atuação individualizada por parte de cada membro que ocupa um cargo de chefia, o que pode ser identificado nos relatos abaixo:

E aí, eu realmente acho que ele, hoje, é um peixe fora d’água. Talvez, nos últimos meses, com a mudança de uma outra executiva, ele tenha ficado menos fora d'água, mas eu acho que ele é um peixe fora d'água dentro da SEPLAG como um todo [Entrevista 2].

Não, eu acho que é... Cada um tem as suas características. Eu acho. Na minha percepção. Que não é uma coisa que vem do estilo SEPLAG. Acho que cada um tem a sua característica [Entrevista 10].

De maneira geral, ficaram evidenciados no conteúdo das entrevistas quatro níveis de chefia percebidos pelos gestores organizacionais: o primeiro deles corresponde àquele ocupado pelos cargos de gerências (seja gerência ou gerência geral); o segundo é representado pelos indivíduos que ocupam cargo de secretários executivos; o terceiro nível é atribuído ao secretário da pasta (planejamento e gestão); e o último nível possui como referência a figura do governador de Pernambuco. Nota-se que há uma predominância em atribuir às chefias dos dois primeiros níveis os aspectos relacionados à comunicação e gestão de pessoas, enquanto que aos dois níveis seguintes são atribuídos aspectos sobre processos de trabalho. Observa-se também que quanto maior o nível de chefia, mais difícil o acesso e mais estreito é o canal de comunicação. 0 Quadro 5 exemplifica as considerações feitas:

Quadro 5- Níveis de Chefia como referência na Seplag-PE

\begin{tabular}{|c|c|}
\hline Nível de Chefia & Segmentos \\
\hline 4 - Governador & $\begin{array}{l}\text { Veja, a nossa secretaria tem um viés político grande. Infelizmente, a gente depende, digamos, da mão do } \\
\text { governador puxando algumas coisas pra acontecer (...)[Entrevista 1]. } \\
\text { E é um problema desse novo modelo, da forma como tá... não do novo modelo, na verdade, do antigo que tá } \\
\text { defasado... é essa questão da gente não ter o respaldo da liderança máxima. A gente chegava nas se- } \\
\text { cretarias, dizer "vai ter reunião com governador", e a gente conseguia informação, a gente conseguia } \\
\text { marcar reunião, a gente conseguia... [Entrevista 26]. }\end{array}$ \\
\hline $\begin{array}{c}3 \text { - Secretário da } \\
\text { Pasta }\end{array}$ & $\begin{array}{l}\text { Mas em relação à liderança maior da SEPLAG, o alto escalão, eu percebo que deixa um pouco a dese- } \\
\text { jar, porque muitas vezes não tem muito esse perfil de negociar ou de conversar com o resto dos gestores da } \\
\text { equipe. Eu percebo mais um caráter impositivo, como eu disse, dele... "e realmente é isso e aceitem"... e eu } \\
\text { acho que isso interfere muito na satisfação de muita gente que trabalha aqui [Entrevista 7]. } \\
\text { o secretário de pasta, sinceramente, nunca vi nem comi, eu só ouço falar. Não tenho... sabe. Se passar } \\
\text { por mim talvez eu saiba só quem é, mas eu não consigo enxergar. Que eu também não sei se é uma questão } \\
\text { de... por ser só uma gestora [Entrevista 18]. }\end{array}$ \\
\hline $\begin{array}{l}2 \text { - Secretários } \\
\text { Executivos }\end{array}$ & $\begin{array}{l}\text { Havia um problema inicial quando eu cheguei... com relação a gestão anterior, que ocupava mais o cargo lá } \\
\text { de cima, secretaria executiva... de comunicação, de falta de alinhamento, ficava muito por ali. [Entre- } \\
\text { vista 6]. }\end{array}$ \\
\hline
\end{tabular}




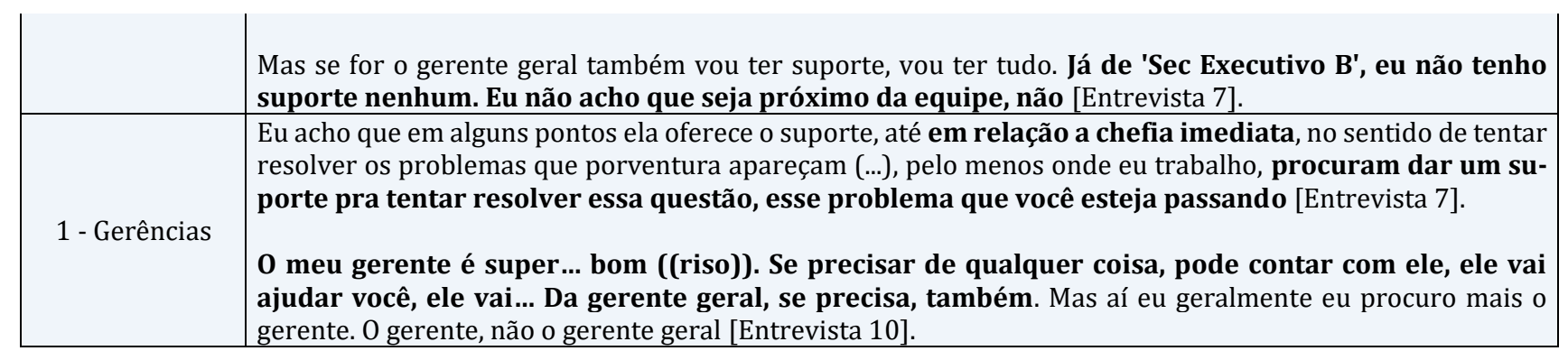

Fonte: Elaborado pelos autores (2018)

A figura do governador como referência na avaliação de suporte organizacional da Seplag-PE pode ser atribuída não apenas do vínculo formal dos gestores como servidores de Pernambuco, mas sobretudo à proposta do modelo Todos por Pernambuco que preceitua, dentre outras características, a forte participação da liderança máxima do estado como fator de sucesso, sendo sua participação fundamental no desenvolvimento das atividades coordenadas pela secretaria de planejamento.

Embora muitas vezes tenham sido feitas referências negativas sobre percepção de suporte por parte da categoria analisada - muitas vezes ocasionada por falta de alinhamento de diretrizes da própria Seplag-PE, como foi observado na categoria de Gestão do Desempenho, existe o reconhecimento da dificuldade em realizar esse papel:

Eu só acho que a gente às vezes tem que... 0 gerente tem que ser um para-choque, e isso é difícil. Um para-choque entre a demanda do executivo e a demanda da equipe [Entrevista 12].

Percebe-se que o enfrentamento a essas dificuldades é feito de modo bastante personalista, por iniciativa de cada indivíduo que atua em cargos de chefia e que a Seplag-PE necessita desenvolver ações que mitiguem problemas relacionados a esta categoria, uma vez que a organização é corresponsável pelo direcionamento das ações de seus membros.

Os achados sugerem que minimizar problemas relacionados a esta categoria consiste não só em ajustes internos da organização, seja por meio de ações de gestão de pessoas mais efetivas em aspectos de liderança ou de melhor alinhamento e disseminação das estratégias e diretrizes organizacionais, mas também na revisão do modelo de gestão Todos por Pernambuco, uma vez que o papel da chefia destacado como elemento essencial do modelo, como já exposto, afeta negativamente a percepção de suporte dos gestores governamentais.

- Suporte social no trabalho:

A categoria de Suporte Social no Trabalho diz respeito à percepção dos indivíduos sobre as relações interpessoais e ao apoio recebido dos pares e chefes. Esta é a categoria que reúne mais elementos de avaliação positiva quanto à percepção de suporte organizacional, o que pode ser sintetizado pelos depoimentos a seguir:

Eu vejo que os colegas são receptivos, também nunca tive grandes dificuldades de relacionamento, grandes fronteiras. Vejo que há uma cultura colaborativa. Em todos os locais que eu passei, realmente... [Entrevista 6].

Eu acho que a gente sempre recebe um suporte, de qualquer forma, seja técnico, emocional, seja o que for. Sempre tem alguém lhe ajudando. Podia ser melhor ou pior? $\mathrm{Sim}$, com certeza. Mas sempre existe alguém ajudando [Entrevista 11].

Acho que o melhor da SEPLAG são as relações interpessoais. As pessoas são bem legais... Inclusive, quando a gente entrou aqui que era muito difícil, acho que o grande suporte eram os colegas. Porque como a gerência não era de analistas concursados, era mais difícil ainda. Então a convivência é que sustentava a gestão, era muito complicado. Mas acho que a gente faz amigos pra aqui e pra fora da SEPLAG também [Entrevista 20].

Observa-se ainda que a PSO quanto à categoria em análise se divide em dois tipos principais: a) Suporte Social Informacional - relacionado mais ao suporte técnico oferecido para que os sujeitos possam realizar suas atividades; b) Suporte Social Emocional - relacionado à demonstração de cuidado e sentimentos com o outro (Siqueira, 2008). Os depoimentos dos entrevistados 19 e 15 exemplificam, respectivamente, os tipos de suporte social identificados: 
Agora que eu mudei de setor e tive que aprender tudo, foi um suporte muito bom, que eu recebi. Tive que aprender e todo mundo que eu tive que perguntar, tive que entender alguma coisa, todo mundo teve uma disponibilidade muito boa de me ensinar [Entrevista 19].

Principalmente suporte emocional. Às vezes eu passei por muitos problemas e, pra mim, vir pro trabalho era uma coisa boa, encontrar o povo, sabe... E até técnico também, porque eu sei que no dia que precisar do pessoal, eu sei que posso contar. Não tenho a menor dúvida [Entrevista 15].

De modo geral, houve uma recorrência maior no conteúdo das entrevistas ao suporte técnico em detrimento do suporte emocional, o que demonstra um entendimento convergente com os achados de Andrade, Estivalete e Gomes (2013), que apontam, em estudo no setor bancário, existir nas organizações públicas maior incidência do suporte social informacional.

A avaliação positiva do suporte percebido na Seplag-PE quanto a esta categoria pode ser atribuído a uma nova imagem do servidor público que afasta a concepção do servidor descomprometido com os processos da administração pública, imagem esta também exaltada no modelo de gestão Todos por Pernambuco. Tal concepção contribui para o sentimento de solidariedade entre os colegas de trabalho e a consolidação da imagem do serviço público como um produto mais amplo que ultrapassa o foco de desempenho meramente individual.

- Ascenção e salários:

Há uma percepção positiva dos gestores governamentais quanto ao salário recebido, mesmo existindo preocupação quanto ao tempo sem reajuste salarial e a possível defasagem ao longo do tempo, caso não sejam efetivadas ações nesse sentido. Embora os reajustes salariais sejam definidos por meio de negociações entre o sindicato, setores específicos da Secretaria de Administração e representantes do gabinete do governador, nota-se que há uma transferência de responsabilidade para a Seplag-PE, o que pode ser evidenciado no depoimento dos entrevistados 1 e 19 do Quadro 6. De modo geral, os entrevistados gostam do salário que recebem e afirmam que é um salário valorizado quando comparado ao de outros profissionais (segmentos de fala dos entrevistados 11, 13, 19 e 27 do Quadro 6).

Quadro 6- Segmentos de fala sobre Salário

\begin{tabular}{|c|l|}
\hline Entrevistado & \multicolumn{1}{c|}{ Segmento } \\
\hline Ent1 & $\begin{array}{l}\text { Acho que isso também faz com que talvez algumas pessoas queiram sair da SEPLAG. Eu mesma já me } \\
\text { questionei muitas vezes se eu deveria permanecer ou se eu deveria continuar estudando pra ir pra outro local, } \\
\text { porque infelizmente a gente já teve perdas salariais que acumulam, sei lá, 23\%... }\end{array}$ \\
\hline Ent11 & $\begin{array}{l}\text { Eu acho que hoje, dentro da SEPLAG, nós temos uma coisa bastante boa, muito boa, que é relação a salário, } \\
\text { antes de qualquer coisa, e isso é bom, independente de estar defasado ou não. No mercado não tá tão simples } \\
\text { ter esse nosso salário. }\end{array}$ \\
\hline Ent19 & $\begin{array}{l}\text { (...) a gente teve, quer queira, quer não, a reestruturação da carreira e poucas carreiras aqui no estado, hoje, } \\
\text { pagariam o salário que a gente recebe. Isso aí a gente não pode reclamar. }\end{array}$ \\
\hline Ent27 & $\begin{array}{l}\text { Quanto ao salário, tá defasado. A gente teve um momento bom, quando teve a nova tabela, e agora isso já tá } \\
\text { se desfazendo. A gente ainda tem um salário muito bom em relação ao próprio serviço público. }\end{array}$ \\
\hline
\end{tabular}

Fonte: Elaborado pelos autores (2018)

Quanto às possibilidades de promoção e ascensão funcionais, não há a mesma percepção positiva existente quando se fala sobre salários. Observa-se, no conteúdo das entrevistas, uma recorrência quanto à dificuldade de alcançar cargos superiores em razão da pouca oferta de cargos desta natureza e da baixa rotatividade de pessoas que assumem esses cargos, o que pode ser evidenciado pelos depoimentos abaixo:

Mas não vejo que a SEPLAG tem uma política de cargos gerenciais. Então a gente... Por exemplo, tem pessoas que hoje estão há 8 anos com uma função, já mudaram de um núcleo pra outro, mas por que não dá oportunidade de outras pessoas também desenvolverem essa capacidade? [Entrevista 1].

Horrível. Quase nula. Quase nula. Os cargos são loteados, quem é gerente é gerente ad eternum, garantido. (...) Porque cria raízes, quando a pessoa chega no cargo [Entrevista 11].

Possibilidade de ascensão. Olhe, eu acho que é muito político. Muito político, na minha visão [Entrevista 13]. 
Schikmann (2010) destaca que a proteção ou privilégio de cargos e funções são elementos que funcionam como inibidores de comportamentos que busquem resultados organizacionais. Nesse contexto, foi destacada a necessidade de se ter critérios mais objetivos para que as pessoas possam mais bem se preparar ou entender quais habilidades e características requisitadas para assumirem os cargos. Nesse sentido, foram elogiadas iniciativas de seleções internas realizadas em 2018:

Mas ultimamente tem tido seleções internas de uma forma mais, digamos assim, com critérios objetivos. Até um estímulo para quem não tem o perfil, quem ainda não conseguiu se capacitar, levar mais a sério o próprio $\mathrm{PFC}$, que foi até critério no núcleo de ciências de dados. A pertinência, a trilha de formação escolhida foi levada em consideração pra ocupar essas funções. Então isso também foi um ganho [Entrevista 6].

É importante destacar que - no que diz respeito a ações relacionadas ao crescimento profissional, salários e promoções -, as organizações privadas lidam com maior variedade de condições e oportunidades que as organizações públicas (Bergue, 2010). Essa limitação inerente ao setor público também foi observada, sobretudo quanto à ascensão funcional como forma de reconhecimento:

E aí também tem um limite do serviço público pra fazer isso. Eu me pego muito pensando nisso, sabe, sobre como o serviço público pode motivar os servidores e reconhecer dentro dessas limitações. (...) Se não pode rodiziar funções, rodiziar cargos... Então como é que você reconhece de outras formas? Eu acho isso é um desafio do serviço público [Entrevista 17].

Embora haja o reconhecimento de questões próprias do setor público como limitadoras de uma melhor gestão de promoções e salários, a ascensão foi observada neste estudo de caso como um elemento influenciador da percepção negativa dos gestores governamentais quanto ao suporte organizacional.

- Carga de trabalho:

A categoria evidenciada por Tamayo e Tróccoli (2002) foi denominada "sobrecarga de trabalho", sendo relacionada às demandas excessivas colocadas para os empregados. Observou-se nesta pesquisa, entretanto, a necessidade de renomear a categoria para "carga de trabalho" - como feito por OliveiraCastro, Pilati e Borges-Andradre (1999), uma vez que esta foi considerada um elemento contributivo para a percepção de suporte organizacional, seja ela excessiva ou não.

0 excesso de demandas ou a falta delas afeta a percepção de suporte, uma vez que parece haver o sentimento, no primeiro caso, de falta de preocupação com o bem-estar dos servidores (segmentos de fala dos entrevistados 20 e 22 no Quadro 7) e, no segundo caso, a sensação de subaproveitamento e desvalorização da capacidade de trabalho dos indivíduos (segmentos de fala dos entrevistados 10, 18, 20 e 22 no Quadro 7).

Quadro 7- Segmentos de fala sobre a Carga de Trabalho

\begin{tabular}{|c|l|}
\hline Entrevistado & \multicolumn{1}{c|}{ Segmento } \\
\hline Ent10 & $\begin{array}{l}\text { Eu acho que eu fico um tempão ociosa. Entendeu? Eu tenho as reuniões, eu atualizo as coisas, mas depois } \\
\text { eu fico bem ociosa. Poderia aproveitar melhor o meu tempo. }\end{array}$ \\
\hline Ent20 & $\begin{array}{l}\text { Tipo, de trabalho mesmo é muito diferente. Muito diferente. Você se sente até, às vezes, subutilizado, sabe, } \\
\text { eu me sinto muito assim, por ter feito tanta coisa já e não conseguir fazer aqui. Você não vê as coisas } \\
\text { acontecendo. }\end{array}$ \\
\hline Ent22 & $\begin{array}{l}\text { A carga de trabalho, veja, eu acho muito tranquilo, quanto a trabalho, e inclusive é desestimulante às } \\
\text { vezes. }\end{array}$ \\
\hline $\begin{array}{l}\text { Muito diferente. Muito diferente do que era no começo. Quando eu falo, do começo da carreira ainda, } \\
\text { em 2011. (...) Agora eu acho que tá bem mais tranquilo, as pessoas estão com muito tempo disponível } \\
\text { para pouco trabalho. (...) Quando eu falo pouco trabalho, significa que nós não estamos, na minha leitura, } \\
\text { sendo puxados pra o trabalho. (...) Então eu acredito que nós estamos funcionando não a pleno vapor, a } \\
\text { gente tá funcionando ainda com muita possibilidade de avançar no trabalho, avançar em termos de } \\
\text { quantidade de trabalho. }\end{array}$ \\
\hline
\end{tabular}

Fonte: Elaborado pelos autores (2018)

Todos os entrevistados, quando solicitados que comentassem sobre a carga de trabalho atual na Seplag-PE, qualificaram o item em características que podem ser sintetizados com pelo menos uma dessas três classificações: sazonalidade, má distribuição e capacidade ociosa, o que mostra a necessidade 
de melhor distribuir não só as demandas de trabalho, mas também de redimensionar as equipes.

- Suporte material:

O suporte material oferecido pela Seplag-PE pode ser dividido em quatro subcategorias, quais sejam: i) instalações físicas, ii) máquinas e equipamentos, iii) tecnologia e softwares e iv) recursos financeiros.

No geral, existe uma percepção positiva quanto ao suporte material oferecido pela instituição, sobretudo quando há comparação das duas primeiras subcategorias (instalações físicas e máquinas e equipamentos) com outros órgãos de Pernambuco, o que pode ser evidenciado nos seguintes depoimentos: Satisfatório. Satisfatório, também sempre comparando com a realidade de outros órgãos do próprio estado, parece eu a gente tem até realidades diferentes, tá em outro órgão. Mas eu vejo... até a estrutura da SEPLAG você vê que é diferenciada [Entrevista 6].

Eu avalio como bom. É bom. A estrutura física da gente é uma estrutura física boa, em comparação com muitos outros órgãos do estado, é bom. As instalações são boas. (...) 0 material também, a gente tem equipamento bom, notebook, tudo o mais. A gente tem acesso fácil a suprimentos do dia a dia, de uso corrente... [Entrevista 21].

No que diz respeito a tecnologias e softwares, se observam pontos de melhoria em questões como: a capacitação dos servidores para utilizar softwares disponíveis na organização; a atualização de softwares utilizados para desenvolvimento das atividades; e a contínua inovação e integração de ferramentas e sistemas que possam gerar melhores resultados.

Ela fornece, digamos, computadores, razoavelmente bons, mas a gente não tem um suporte do tipo capacitação no uso daqueles softwares, por exemplo, dos softwares que estão no computador [Entrevista 4].

Com relação a software, soluções de tecnologia da informação, de BI é que a gente poderia avançar bastante, com relação a isso [Entrevista 6].

Eu acho que a SEPLAG peca, sabe. (...) Às vezes a gente trabalha com o básico. 0 Windows, por exemplo, desatualizado... Acho que a SEPLAG precisaria melhorar esse suporte. A questão de tecnologias, mesmo, acesso a programas e tal, pra gente poder evoluir também, no nosso trabalho [Entrevista 13].

Quanto aos recursos financeiros, há uma percepção negativa concentrada principalmente na Secretaria Executiva de Gestão por Resultados pautada nos valores das diárias recebidas para viagens, que se mostra insuficiente para cobrir os custos dos GGPOG que precisam pernoitar em outras cidades para discutir resultados com gerências locais. Os depoimentos a seguir exemplificam:

(...) hoje em dia a gente tem uma diária que não cobre os custos que a gente vai ter quando a gente viaja. Se a gente não tiver um alojamento da GERES, ou da GRE, enfim, ou da AIS, a gente não tem onde ficar e a gente tem que tirar do próprio bolso pra complementar uma diária de um hotel porque a diária da SEPLAG não é suficiente. Isso é muito desestimulante (...) [Entrevista 1].

Talvez as diárias. Talvez as diárias a gente teria um pouco de... Vai, a gente precisa melhorar. A gente precisa melhorar porque pra gente fazer algumas visitas a unidades no interior, unidade que a gente pernoitar, essa diária é insuficiente. Por vezes, eu tive que tirar do meu bolso pra poder franquear a minha estadia. Por vezes não, várias vezes [Entrevista 9].

Devido, sobretudo, à coordenação dos Pactos de Resultados, os gestores que integram a SEGPR possuem maior necessidade de pernoitar fora da capital pernambucana, monitorando dados e discutindo ações de melhoria dos processos e indicadores.

A comparação com outros órgãos do estado mostra-se como determinante na avaliação dos gestores governamentais quanto a esta categoria. O fato da Seplag-PE ser uma das secretarias mais novas, criada no primeiro mandato do então governador Eduardo Campos e ter sido construída como estrutura coordenadora de um modelo de gestão moderno também conferiram à estrutura física elementos diferenciados de outros órgãos mais antigos de Pernambuco. Dentre outras coisas, há móveis planejados, todos os ambientes climatizados, salas de reunião e treinamento e a própria sala de reunião para monitoramento dos indicadores e metas com o governador dão ao prédio uma simbologia e estrutura diferenciadas.

Além disso, a maior parte dos equipamentos foi adquirida pelo estado no mesmo período de entrada dos gestores governamentais, uma vez que a carreira foi criada com o propósito de contribuir especificamente com 
modelo de gestão proposto. Os primeiros gestores ingressaram na instituição no ano de 2010 após concurso público, diferente da maioria dos servidores de outras carreiras que já possuem mais tempo de existência.

- Fatores políticos:

Estudos qualitativos tendem a encontrar categorias que não poderiam ser suscitadas em pesquisas de abordagem quantitativa. Nesse sentido, uma nova categoria observada na análise de conteúdo foi a influência de fatores políticos na percepção de suporte organizacional dos GGPOG. Os fatores políticos também afetam a percepção acerca de outras categorias analisadas, sobretudo quanto:

a) à ascensão e reconhecimento através de cargos (como pode ser observado nas falas dos entrevistados 14 e 20 no Quadro 8); e

b) à gestão do desempenho na organização, principalmente quanto aos processos de trabalho - quando muitas vezes as decisões políticas se sobrepõem aos pareceres técnicos (segmentos de fala dos entrevistados 1, 8, 12 e 23 no Quadro 8).

Quadro 8- Segmentos de fala sobre a categoria Fatores Políticos

\begin{tabular}{|c|l|}
\hline Entrevistado & \multicolumn{1}{c|}{ Segmento } \\
\hline Ent1 & $\begin{array}{l}\text { Nossa secretaria é muito política ainda, infelizmente eu acho que esse é um dos fatores que geram } \\
\text { insegurança nas pessoas, diferentemente, por exemplo, da SAD que faz um trabalho mais operacional. } \\
\text { Como eu disse aqui, a gente depende da força do governador puxando o Pacto para que ele aconteça. } \\
\text { Então se esse Pacto não acontecer, a gente se sente frustrado (...) }\end{array}$ \\
\hline Ent8 & $\begin{array}{l}\text { Em termos de atividade geral, é você olhar como um todo. Não as caixinhas das atividades dentro das secre- } \\
\text { tarias executivas. Quando você vê o todo, as pessoas se desmotivam muito mais por questões que você } \\
\text { faz uma atividade legal, mas aquilo ali não se torna uma coisa suficiente pra ter uma decisão técnica, } \\
\text { e acaba ficando uma decisão política. }\end{array}$ \\
\hline Ent12 & $\begin{array}{l}\text { É como se às vezes quisesse procurar trabalho pra um grupo específico quando, na verdade, tudo depende do } \\
\text { nível de serviço que você quer ofertar. É uma coisa que ainda é difícil de equalizar e tem esse viés político. } \\
\text { Não é só técnico. }\end{array}$ \\
\hline Ent14 & $\begin{array}{l}\text { Eu acho assim, que o primeiro fator é essa coisa da política. Os cargos, as pessoas estão ali não por } \\
\text { competência, a princípio. Tem muita gente incompetente que tem cargo. Mas por decisões de política } \\
\text { mesmo. O secretário executivo vai ser aquele que o governador tiver interesse. }\end{array}$ \\
\hline Ent23 & $\begin{array}{l}\text { Acho que é uma entrega importante. Fico com pena quando usa pra fins polí/... fico arretado. Essas mu- } \\
\text { danças de pasta, só porque não é com vínculo político, fico arrasada. Não queria que acontecesse. (...) Essa } \\
\text { questão de mudar o secretário de pasta por causa de cadeira política, isso também desmotiva. Porque } \\
\text { muda, aí muda tudo. Pro ano que vem mesmo, já tá pensando “quem é que vai vir?”. Eu acho isso muito } \\
\text { triste. }\end{array}$ \\
\hline
\end{tabular}

Fonte: Elaborado pelos autores (2018)

Tais achados são importantes não só para contribuir com a teoria da PSO, mas também para identificar lacunas importantes no próprio processo de modernização da Administração Pública. BresserPereira (2004, p.12) afirma que "o gestor público nas democracias modernas não é um mero aplicador das leis e políticas públicas definidas pelos políticos eleitos, mas alguém que toma decisões com autonomia". Embora muitos avanços tenham sido observados, a autonomia na tomada de decisões técnicas dos gestores governamentais é frustrada por fatores políticos.

Embora não tenha sido, na análise de conteúdo (figura 2), a categoria com maior quantidade de recorte de conteúdo identificado, observa-se que a categoria tem um papel de influência bastante negativa na formação geral da percepção dos gestores quanto ao suporte oferecido pela organização. A percepção negativa está amparada nas disfunções ainda predominantes do funcionalismo público tolhido pelo jogo de interesses políticos.

Como destaca Ana Paula Paes de Paula (2005), estabelecer uma combinação adequada entre a administração e a política é um desafio importante para os governantes e pesquisadores, considerando a lógica própria da Administração Pública.

\section{Considerações Finais}

Este estudo explorou de forma aprofundada a realidade de uma organização pública estadual, analisando a percepção de gestores públicos quanto ao suporte organizacional oferecido. Além de investigar um tema e contexto ainda pouco pesquisados, utilizou uma abordagem qualitativa de pesquisa em um contexto de análise no qual predominam os métodos quantitativos.

Quanto às categorias de Suporte Organizacional reconhecidas pela literatura e utilizadas neste 
estudo, foi sugerida a manutenção da nomenclatura utilizada por Oliveira-Castro, Pilati e Borges-Andrade (1999) em uma delas (Carga de Trabalho), uma vez que se constatou ser a carga de trabalho um elemento contributivo para a percepção de suporte organizacional, seja ela excessiva ou não. Foi também sugerida a inclusão da categoria Fatores Políticos como integrante das categorias já estabelecidas, por terem sido recorrentes as menções a aspectos desta natureza como formadores da PSO dos gestores governamentais da Seplag-PE.

Observou-se que existe uma percepção negativa dos gestores governamentais quanto ao suporte oferecido pela Secretaria de Planejamento e Gestão de Pernambuco. Com exceção das categorias de Suporte Material, Suporte Social e Salários, as demais contribuíram significativamente para este resultado. De modo geral, o estudo contribuiu para aprofundar o entendimento sobre o processo de formação das impressões dos servidores públicos quanto ao suporte organizacional, o que é fundamental para identificar elementos condicionantes não só do desempenho dos servidores públicos, mas do bem-estar, do envolvimento e do comprometimento como resposta aos esforços organizacionais.

Destaca-se como grande contribuição do estudo a sugestão da categoria de Fatores Políticos como integrante do Suporte Organizacional e, especificamente no caso analisado, a influência negativa desse item na percepção dos gestores entrevistados, o que sugere que a estrutura de gestão de pessoas da Administração Pública ainda caminha a passos lentos na valorização de elementos técnicos em detrimento de articulações políticas. Sobretudo por ter sido realizado no órgão gestor do modelo de gestão Todos por Pernambuco, este estudo de caso aponta achados relevantes que podem nortear ações nos demais órgãos estaduais com o objetivo de discutir e aprimorar aspectos comportamentais na estrutura pública.

Recomenda-se a realização de mais estudos no setor público, em seus diferentes desenhos estruturais, nos quais se investigue o Suporte Organizacional Percebido pelos servidores. Sugere-se que em tais estudos sejam utilizados métodos qualitativos, como feito nesta pesquisa, a fim de melhor observar a consistência da categoria "Fatores Políticos" sugerida neste artigo.

\section{Referências}

Al-Hussami, M.; Hammad, S.; \& Alsoleihat, F. (2018). The influence of leadership behavior, organizational commitment, organizational support, subjective career success on organizational readiness for change in healthcare organizations. Leadership in Health Services.

Andrade, T., Estivalete, V. F. B., \& Gomes, T. C. Suporte social e organizacional no trabalho: um diagnóstico no setor bancário público e privado. RECADM | vol. 12 | n. 1 | p. 23-38 | Jan-Abr/2013

Aselage, J., \& Eisenberger, R. (2003). Perceived organizational support and psychological contracts: A theoretical integration. Journal of Organizational Behavior, v. 24, n. 5, p. 491- 509.

Bardin, L. (2016). Análise de conteúdo. Lisboa, Portugal; Edições 70, LDA.

Bastos, A. V. B., MAIA, L. G., Rodrigues, A. C. A., Macambira, M. O., \& Borges-Andrade, J. E. (2014). Vínculos dos indivíduos com a organização: análise da produção científica brasileira 2000-2010. Psicologia: Teoria e Pesquisa, 30(2), 153-162.

Bergue, S. T. (2014). Gestão estratégica de pessoas no setor público. São Paulo: Atlas.

Berthelsen, H., Hjalmers, K., \& Soderfeldt, B. (2008). Perceived social support in relation to work among Danish general dental practitioners in private practices. European Journal of Oral Sciences, vol. 116, n. 2, p. 157-163.

Bresser-Pereira, L. C. (2004). Instituições, bom Estado, e reforma da gestão pública. In: BIDERMAN, C. ARVATE, P. (Orgs.). Economia do setor público no Brasil. São Paulo: Campus Elsevier, 3-15.

Cruz, M. S. M. da, Marini, C.; \& Lemos, M. (2014). Modelo de gestão Todos por Pernambuco: características e avanços. In: CONGRESSO CONSAD DE GESTÃo PÚBLICA. Anais... Brasília, 7.

De Paula, A. P. P. (2005). Administração pública brasileira entre o gerencialismo e a gestão social. $R A E$ Revista de Administração de Empresas, vol. 45, n. 1.

Diógenes, L. C., Paschoal, T., Neiva, E. R., \& Meneses, P. P. M. (2016) Intenção de rotatividade e percepção de suporte organizacional em um órgão público federal. Rev. Serv. Público, Brasília 67 (2) 147-172 abr/jun.

Eisenberger, R., Huntington, R., Hutchison, S., \& Sowa, D. (1986). Perceived organizational support. Journal of applied psychology, vol. 71, n. 3, p. 500-507.

Estivalete, F. B. V., Andrade, T., Faller, L. P., Stefanan, A., \& Souza, D. L. (2016). Suporte social e suporte organizacional como antecedentes do bem-estar no trabalho: a perspectiva de colaboradores de uma 
empresa de logística ferroviária. Revista de Administração da UNIMEP, 14(2).

Fandiño, A., Souza, M., Formiga, N., Menezes, R., \& Bentes, S. R. (2015). Organizational anomie, professional self-concept and organizational support perception: theoretical model evidences for management. International Journal of Business and Social Science, 6 (11), 1-10.

Fernandes, C. M., Siqueira, M. M. M., \& Vieira, A. M. (2014). Impacto da percepção de suporte organizacional sobre o comprometimento organizacional afetivo: o papel moderador da liderança. Revista Pensamento Contemporâneo em Administração, v. 8, n. 4, p. 140-162.

Gomide, J.R, S., Guimarães, L. C., \& Damásio, L. F. Q. (2004). Construção e validação de um instrumento de medida de percepção de suporte social no trabalho. In: II Seminário GIBEST, do Grupo de Interinstitucional de Pesquisa sobre Bem-estar, Suporte Social e Trabalho. Uberlândia, Brasil.

Gouldner, A. W. (1960). The norm of reciprocity: a preliminary statement. American Sociological Review, 25, 161-178.

Giorgi, G., Dubin, D., \& Fiz, P. J. (2016). Perceived organizational support for enhancing welfare at work: a regression tree model. Front. Psychol. 7: 1770.

Karatepe, 0. M. (2015). Do personal resources mediate the effect of perceived organizational support on emotional exhaustion and job outcomes?. International Journal of Contemporary Hospitality Management, 27(1), 4-26.

Lewis, G. B., \& Frank, S. A. (2002). Who wants to work for government? Public Administration Review, vol. 62, n. 4, p. 395-404.

Haguette, T. M. F. (1997). Metodologias qualitativas na Sociologia. 5a Edição. Petrópolis: Vozes, 1997.

Medeiros, S. B. de. (2013). Percepção de suporte e comprometimento organizacional: um estudo nas unidades de criminalística da Polícia Federal. (Dissertação de mestrado em Administração). Escola Brasileira de Administração Pública e de Empresas, Centro de Formação Acadêmica e Pesquisa.

Merriam, S. B. (2009). Qualitative research: case study, applications in education. San Francisco: JosseyBass, 304p.

Merriam, S. B., \& Tisdell, E. J. (2016). Qualitative research: a guide to design and implementation. San Francisco: Jossey-Bass.

Miles, M. B., \& Huberman, A. M. (1994). Qualitative Data Analysis: an expanded sourcebook. 2⿳⺈ ed. London: Sage.

Moraes, R. A. S.; \& Bastos, S. A. P. B. (2017). Associação Entre as Dimensões do Suporte Organizacional Percebido e a Intenção de Saída do Trabalho. EnANPAD, 2017. In: Encontro da Associação Nacional dos Programas de Pós-graduação em Administração - EnANPAD, 2017, São Paulo. Anais... São Paulo: ANPAD. Moura, A. L. N., \& Souza, B. C. (2016). Gestão estratégica de pessoas na administração indireta do setor público federal: na prática, ainda um discurso. Revista do Serviço Público, v. 67, n. 4, p. 575-602.

Oliveira-Castro, G. A. de, Pilati, R., \& Borges-Andrade, J. (1999). E. Percepção de suporte organizacional: desenvolvimento e validação de um questionário. Rev. Adm. contemp. vol. 3 no.2 Curitiba Mai/Ago.

Patton, M. Q. (2002). Qualitative research and evaluation methods. 3. ed. California: Sage Publications. Pereira, S. C. S. (2016). Suporte Organizacional Percebido na Marinha do Brasil: Em Busca do Fogo Sagrado. Tese (Doutorado em Administração) - Pontifícia Universidade Católica. Rio de Janeiro, p. 178. Schikmann, R. (2010). Gestão estratégica de pessoas: bases para a concepção do curso de especialização em gestão de pessoas no serviço público. ENAP, p. 9-28.

Secretaria de Planejamento e Gestão (Seplag) (2018). Principais atividades. Pernambuco, 2018. Disponível em: http://www.seplag.pe.gov.br/web/inst/institucional-seplag. Acesso: 18/04/2018.

Shoss, M. K., Eisenberger, R., Restubog, S. L. D., \& Zagenczyk, T. J. (2013). Blaming the organization for abusive supervision: the roles of perceived organizational support and supervisor's organizational embodiment. Journal of Applied Psychology, v. 98, n. 1, p. 158 - 162.

Siqueira, M. M. M. (2008). Construção e validação da escala de percepção de suporte social. Psicologia em Estudo, 13(2), 381-388.

Souza, E. P. de. \& Marques, A. L. (2014). Comprometimento organizacional e personalidade: considerações sobre a influência dos traços no comprometimento. EnANPAD, 2014. In: Encontro da Associação Nacional dos Programas de Pós-graduação em Administração - EnANPAD, 40, 2014, Rio de Janeiro. Anais... Rio de Janeiro: ANPAD.

Tamayo, M. R., Pinheiro, F. A., Tróccoli, B. T., \& Paz, M. G. T. (2000). Construção e validação da escala de suporte organizacional percebido (ESOP) [Resumo]. Reunião Anual da Sociedade Brasileira para o Progresso da Ciência. Anais... Brasília, DF. Brasil, 52. 
Tamayo, M. R., Tróccoli, B. T. (2002). Exaustão emocional: relações com a percepção de suporte organizacional e com as estratégias de coping no trabalho. Estudos de Psicologia, 7 (1), 37-46.

Wayne, S., Shore, L., Bommer, W., \& Tetrick, L. (2002). The role of fair treatment and rewards in perceptions of organizational support and leader-member exchange. Journal of applied psychology, vol. 87, n. 3, p. 590-598.

Zagenczyk, T. J., Scott, K. D., Gibney, R., Murrell, A. J., \& Thatcher, J. B. (2010). Social influence and perceived organizational support: a social networks analysis. Organizational Behavior and Human Decision Processes, vol.111, n.2, p. 127-138.

Zanelli, J. C., Borges-Andrade, J. E., \& Bastos, A. V. B. (2014). Psicologia, organizações e trabalho no Brasil. 2 ed.. Porto Alegre: Artmed. 